\title{
PENGATURAN PEDAGANG KAKI LIMA (PKL) \\ DI LINGKUNGAN TEGALBOTO \\ BERDASARKAN PERATURAN DAERAH NOMOR 6 TAHUN 2008 \\ KABUPATEN JEMBER
}

\section{REGULATION OF STREET VENDORS IN TEGAL BOTO \\ BASED ON REGIONAL REGULATION NUMBER 6 OF 2008 \\ JEMBER DISTRICT}

\author{
Oleh : \\ Alissa Ernawati Adisiswanto ${ }^{1}$ \\ Fakultas Ilmu Sosial dan Politik Universitas Mochammad Sroedji Jember \\ Jl. Sriwijaya No. 32 Jember 68124 \\ alissaerna@gmail.com
}

\begin{abstract}
Disruption of dicipline and cleanliness in urban areas of Jember Regency caused by the presence of street vendors occupying the sidewalk and shoulder area, causing pedestrians and passing vehicles to be disturbed. The purpose of this observation was to determine regulation and arrangement of street vendors in the city of Jember based on Regional Regulation No. 6 of 2008. This observation uses descriptive qualitative methods, exploring the effectiveness of Regional Regulation No. 6 of 2008 concerning Street Vendors in Jember Regency, especially on the existence of Street Vendors in Tegalboto, Jember Regency was the focus of research. Data and information in the observation consisted of interviews, documentation, archives and books related on observation. Data analysis techniques are carried out through the process of data collection, data reduction, data presentation and summary. Data validation used is data triangulation. The results of research conducted by the author that the implementation of street vendor control has been going well even though it is less effective. Inhibitiary factors come from internal and external. Internal barriers are lack of coordination between local government organizations, external barriers arise from street vendors who do not relocated at all.
\end{abstract}

Keywords: Structuring of street vendors in Tegalboto, policy effectiveness 


\begin{abstract}
Abstrak
Gangguan ketertiban dan kebersihan di wilayah perkotaan Kabupaten Jember adalah diantaranya disebabkan keberadaan Pedagang Kaki Lima (PKL) yang menempati area trotoar dan bahu jalan, sehingga mengakibatkan pejalan kaki dan kendaraan yang melintas terganggu. Tujuan penelitian ini adalah untuk mengetahui pengaturan dan penataan Pedagang Kaki Lima (PKL) yang ada di kota Jember berdasarkan Peraturan Daerah Nomor 6 Tahun 2008. Penelitian ini menggunakan metode kualitatif deskriptif, membahas efektivitas Peraturan Daerah Nomor 6 Tahun 2008 tentang Pedagang Kaki Lima di Kabupaten Jember, terutama pada keberadaan Pedagang Kaki Lima (PKL) di Lingkungan Tegalboto Kabupaten Jember menjadi fokus penelitian. Data dan informasi dalam penelitian terdiri dari hasil wawancara, dokumentasi, arsip-arsip dan buku yang berkaitan dengan fokus penelitian. Teknik analisis data yang dilakukan melalui proses pengumpulan data, reduksi data, penyajian data dan penarikan kesimpulan. Validasi data yang digunakan triangulasi data. Hasil penelitian yang dilakukan oleh penulis bahwa implementasi penertiban Pedagang Kaki Lima sudah berjalan dengan baik meskipun kurang efektif. Faktor penghambat berasal dari internal dan eksternal. Hambatan dari internal adalah kurangnya koordinasi antar organisasi pemerintah daerah, hambatan eksternal muncul dari Pedagang Kaki Lima yang tidak seluruhnya melakukan relokasi.
\end{abstract}

Kata Kunci: Penataan PKL di Lingkungan Tegalboto, Efektivitas kebijakan 


\section{PENDAHULUAN}

Kabupaten Jember merupakan sebuah kabupaten di Provinsi Jawa Timur yang memiliki luas wilayah kurang lebih 3.293,34 Km2. Kabupaten Jember berbatasan dengan Kabupaten Bondowoso di sebelah utara, Kabupaten Banyuwangi di sebelah timur, Samudera Hindia di sebelah selatan, dan Kabupaten Lumajang di sebelah barat. Kabupaten Jember terdiri dari 31 kecamatan. Kabupaten Jember dikenal sebagai kota pendidikan. Ada Perguruan tinggi negeri dan beberapa Perguruan tinggi swasta. Kabupaten Jember merupakan salah satu kabupaten yang berkembang secara pesat di segala sektor.

Daerah berkembang di kota Jember tepatnya di lingkungan Tegalboto, keberadaan Pedagang Kaki Lima (PKL) merupakan salah satu usaha sektor informal yang tidak dapat dipisahkan dari kompleksitas pembangunan perkotaan, sebagai sebuah kegiatan sektor informal yang memiliki ciri fleksibilitas usaha, dengan modal minimum dan lokasi usaha yang mendekati konsumen.

Dari data yang diperoleh, Pedagang Kaki Lima (PKL) di kecamatan kota (kecamatan Kaliwates, Sumbersari, Patrang) jumlahnya setiap tahun terus bertambah. Yakni tahun 2014 sejumlah 970, tahun 2015 sejumlah 1.077, tahun 2016 sejumlah 1.194, tahun 2017 sejumlah
1.326, tahun 2018 sejumlah 1.211. (Sumber Data: Kantor Satpol PP Kabupaten Jember, Oktober 2018). Di lingkungan Tegalboto, PKL merupakan salah satu mata pencaharian yang tidak membutuhkan kemampuan berfikir yang tinggi sehingga bisa di lakukan oleh semua golongan masyarakat. Di imbangi dengan pertumbuhan penduduk dari tahun ke tahun dan kurang tersedianya lapangan kerja yang memadai bagi masyarakat bawah, inilah salah satu alternatif untuk berprofesi sebagai PKL. Karena banyaknya PKL yang menggunakan trotoar dan bahu jalan untuk berjualan maka membuat arus lalu lintas terganggu sehingga menimbulkan kemacetan di lingkungan Tegalboto Kabupaten Jember sebagai daerah kampus dan perkantoran.

Di Kabupaten Jember, PKL merupakan sektor penting yang harus diperhatikan keberadaannya, demi menjaga keindahan tata kota dan kenyamanan berlalu lintas, tanpa mengesampingkan kebutuhan masyarakat dalam memenuhi kebutuhan hidupnya. Untuk mengatur penataan dan relokasi keberadaan PKL Pemerintah Daerah mengeluarkan Peraturan Daerah Nomor 6 Tahun 2008 tentang Pedagang Kaki Lima di Kabupaten Jember. Sejak dikeluarkannya Peraturan Daerah Nomor 6 Tahun 2008 tentang Pedagang Kaki Lima di Kabupaten Jember, pernah dilakukan 
penataan PKL secara menyeluruh pada tahun 2010 dan tahun 2014. Tetapi sampai sekarang bisa dilihat keberadaan PKL di lingkungan Tegalboto masih menggunakan bahu jalan dan trotoar sehingga mengakibatkan pejalan kaki tidak bisa melewati trotoar, kemacetan arus lalu lintas, kendaraan yang parkir tidak menggunakan bahu jalan dengan teratur, bahkan parkir ditempat yang terdapat rambu larangan untuk berhenti, hal ini disebabkan karena bahu jalan sudah penuh ditempati oleh gerobak maupun tenda PKL yang memajang barang dagangannya. Penelitian ini bertujuan mendeskripsikan efektivitas Peraturan Daerah Nomor 6 Tahun 2008 tentang Pedagang Kaki Lima di Kabupaten Jember yang dilakukan pada penataan dan penertiban PKL di Lingkungan Tegalboto. Sebuah Peraturan Daerah dikeluarkan bertujuan untuk membawa manfaat dan kebaikan pada kehidupan bermasyarakat. Dalam teori implementasi kebijakan,. Abidin (2016:19) mendefinisikan, "Kebijakan sebagai suatu keputusan pemerintah dalam penyelesaian permasalahan permasalahan di masyarakat dan mewujudkan suatu tujuan yang diinginkan masyarakat". Implementasi menurut Tachjan (2008:24), "Diartikan sebagai suatu kegiatan terkait dengan penyelesaian sebuah tugas dengan memakai sarana yang ada dalam mencapai tujuan kebijakan".

\section{TINJAUAN TEORITIS}

Pada kegiatan penelitian ini penulis menerapkan teori implementasi kebijakan yang terbagi dalam empat faktor berikut:

1. Komunikasi

Komunikasi dianggap merupakan faktor penting karena merupakan acuan apakah pelaksana kebijakan dapat mengerti secara persis apa yang akan dikerjakan. Oleh karena itu, informasi untuk pelaksanaan kebijakan harus diinformasikan secara singkat, akurat, jelas serta konsisten pada para pelaksana kebijakan sehingga pelaksanaan kebijakan nantinya tidak meleset dari tujuan/sasaran yang diinginkan. Edward III (dalam Agustino,2014:150), mengukur keberhasilan komunikasi dengan tiga indikator, antara lain Transmisi, Kejelasan dan Konsistensi

2. Sumber Daya

Sumber daya menentukan bagaimana suatu kebijakan dapat berjalan dengan efektif, aktor sumber daya akan menentukan kelayakan dari pelaksanaan kebijakan. Agustino (2014) menjelaskan beberapa indikator dalam faktor sumber daya sebagaimana pendapat Edward III, yaitu berupa Staf, Informasi, Wewenang dan Fasilitas.

3. Sikap Pelaksana (Disposisi)

$$
\text { Apabila mengharapkan }
$$

implementasi kebijakan berlangsung 
dengan baik para pelaksana haruslah memiliki keinginan dan bersedia memberikan waktu, pikiran serta tenaga yang dimilki untuk pelaksanaan kebijakan tersebut. Agustino (2014) menjelaskan poin-poin penting yang menentukan sikap pelaksana menurut Edward III hanya ada 2 subdimensi yaitu Pengangkatan Birokrat dan Insentif.

4. Struktur Birokrasi

Struktur birokrasi akan ikut menentukan kelancaran dari pelaksanaan suatu kebijakan. Meskipun ketiga dimensi implementasi kebijakan diatas berjalan baik, apabila implementasi kebijakan terbentur adanya inefisiensi struktur birokrasi maka keberhasilan implementasi kebijakan akan terganggu. Syafri dan Setyoko (2010:40) berpendapat ada dua hal penting dalam struktur birokrasi, yaitu Standard Operating Procedures (SOP) dan Fragmentasi.

Untuk itu Pemerintah Kabupaten Jember telah mengeluarkan dan menetapkan sebuah kebijakan yang mengatur keberadaan Pedagang Kaki Lima (PKL) yaitu Peraturan Daerah Kabupaten Jember Nomor 6 Tahun 2008. Dari kondisi inilah maka penulis tertarik untuk mengkaji suatu penelitian yang berjudul Pengaturan Pedagang Kaki Lima Di Lingkungan Tegalboto
Berdasarkan Peraturan Daerah Nomor 6 Tahun 2008 Kabupaten Jember

\section{METODE PENELITIAN}

Pada kegiatan penelitian ini penulis menggunakan metode penelitian kualitatif dengan jenis deskriptif dengan pendekatan induktif yang membangun pola, kategori dan temanya dari atas ke bawah menurut (Cresswell: 2016:248). Metode analisis data yang digunakan dalam penelitian yaitu tehnik pengumpulan data dengan menggabungkan pengumpulan data, observasi, wawancara dan dokumentasi, validasi menggunakan triangulasi berdasarkan (Cresswell: 2016:254).

\section{Observasi kualitatif (qualitative} observation) peneliti terjun langsung untuk mengamati perilaku serta aktifitas di lokasi penelitian. Dalam pengamatan ini, peneliti merekam dan mencatat baik dengan cara terstruktur maupun semi terstruktur (dengan mengajukan pertanyaan secara terperinci agar mengetahui lebih dalam) yang di lakukan oleh peneliti ketika berada di lingkungan penelitian.

\section{Wawancara kualitatif (qualitative} interview), peneliti melakukan face-toface interview dengan partisipan, mewawancarai mereka secara langsung, atau terlibat langsung dengan focus group interview yang 
biasanya terdiri dari enam ataupun delapan partisipan per kelompok.

\section{Documentasi kualitatif (qualitative}

documents) selama proses penelitian berlangsung, peneliti bisa mengumpulkan dokumen yang berupa dokumen publik (koran, makalah, laporan kantor) ataupun dokumen prifat (buku harian, surat dan email).

\section{HASIL DAN PEMBAHASAN}

\section{Pelaksanaan Peraturan Daerah} Nomor 6 Tahun 2008 Kabupaten Jember

Lingkungan Tegalboto berada di Kecamatan Sumbersari Kabupaten Jember. Kecamatan Sumbersari resmi dibentuk sebagai salah satu kecamatan di Kabupaten Jember dengan dasar peraturan pemerintah nomor 14 tahun 1976 yang diterbitkan pada tanggal 19 april 1976. Terdapat 7 Kelurahan di Kecamatan Sumbersari yaitu Kelurahan Kranjingan, Kelurahan Wirolegi, Kelurahan Karangrejo, Kelurahan Kebonsari, Kelurahan Sumbersari, Kelurahan Tegalgede dan Kelurahan Antirogo. Berdasarkan hasil survei dan data lapangan, di kelurahan Sumbersari pada 3(tiga) titik jalan yang banyak dijumpai PKL adalah di jalan Jawa, jalan Sumatra dan jalan Kalimantan. Kecamatan Sumbersari memiliki luas wilayah $35,32 \mathrm{~km} 2$.
Luas wilayah di kelurahan Sumbersari tidak didukung dengan sektor lapangan pekerjaan yang memadai. Data pencaharian penduduk Kecamatan Sumbersari yang terbesar adalah pada sektor lainnya (sektor lainnya adalah sektor informal antara lain pedagang kaki lima), tahun 2017 sebesar 18.789 dan tahun 2018 sebesar 33.362 terjadi peningkatan sebesar 14.573, disusul dengan sektor perdagangan 18.316. Keberadaan pedagang kaki lima semakin meningkat di Lingkungan Tegalboto Kecamatan Sumbersari, yakni di jalan Kalimantan pada tahun 2016 sejumlah 106, tahun 2017 sejumlah 111, tahun 2018 sejumlah 127, di jalan Jawa pada tahun 2016 sejumlah 131, pada tahun 2017 sejumlah 139, pada tahun 2018 sejumlah 147, di jalan Sumatra pada tahun 2016 sejumlah 43, pada tahun 2017 sejumlah 46, pada tahun 2018 sejumlah 51. (Sumber data diolah : Satpol PP Kecamatan Sumbersari,2018). Di lingkungan Tegalboto data PKL semakin tahun semakin bertambah, antara lain disebabkan adanya Perguruan Tinggi Negeri dan Swasta yang membuat masyarakat berbondong-bondong menjadi PKL demi memenuhi segala kebutuhan para mahasiswa, tetapi tidak di imbangi dengan kesadaran 
para PKL untuk mentaati peraturan yang sudah di buat oleh pemerintah daerah Kabupaten Jember.

Pada pagi hari saat mulai terjadi aktifitas masyarakat, keberadaan PKL yang kurang tertib sangat menganggu arus lalu lintas, pengguna trotoar dan kebersihan. Ironisnya banyak kendaraan yang parkir sembarangan untuk membeli makanan ataupun kebutuhan di PKL tersebut, sehingga menimbulkan kemacetan. Keberadaan PKL ini bertentangan dengan Peraturan Daerah Kabupaten Jember Nomor 6 Tahun 2008 tentang Pedagang Kaki Lima di Kabupaten Jember, bahwa setiap PKL dilarang ;

a) Membuat bangunan tempat usaha yang bersifat permanen,

b) Menggunakan lahan melebihi ketentuan yang diizinkan,

c) Melakukan kegiatan usaha dengan cara merusak atau mengubah fasilitas umum.

d) Melakukan kegiatan usaha yang dilarang oleh peraturan perundangundangan.

e) Melakukan kegiatan usaha dengan menggunakan kendaraan bermotor.

Implementasi Peraturan Daerah Kabupaten Jember Nomor 6 Tahun 2008 tentang Pedagang Kaki Lima di Kabupaten Jember, antara lain menjadi tanggung jawab Satuan Polisi Pamong
Praja, seperti yang tertuang dalam Pasal 4 butir 1 Peraturan Pemerintah Nomor 6 Tahun 2010 tentang Satuan Polisi Pamong Praja (Satpol PP), bahwa Satpol PP mempunyai tugas menegakkan Peraturan Daerah dan menyelenggarakan ketertiban umum dan ketenteraman masyarakat serta perlindungan masyarakat. Agar suasana yang nyaman dapat tercipta maka implementasi Peraturan Daerah Nomor 6 Tahun 2008 harus ada kerjasama dengan masyarakat utamanya PKL itu sendiri. Pendekatan yang intensif seperti memberikan pembinaan dan sosialisasi mengenai pentingnya Peraturan Daerah Nomor 6 Tahun 2008 agar para PKL memahami dan menyadari program pemerintah tersebut, sehingga para PKL tersebut bersedia untuk direlokasi tanpa adanya paksaan.

Langkah-langkah yang di lakukan oleh Satuan Polisi Pamong Praja diantaranya, melakukan siaran keliling untuk sosialisasi penertiban PKL, memberikan surat edaran, memberikan surat teguran, memberi peringatan dan melakukan penertiban. Setiap tindakan diberikan jangka waktu untuk para PKL agar tidak melakukan pelanggaran, apabila mereka tidak mengindahkan himbauan tersebut maka petugas akan menyita bahkan menangkap dan 
mengkarantina bagi mereka yang menolak, karantina di sini berisi tentang pengarahan dan bimbingan serta memberikan pelatihan supaya mereka punya bekal untuk bekerja di bidang lain dan memberi peluang kerja melalui kerja sama dengan Badan Latihan Kerja (BLK). Apabila mereka masih ingin menjadi KPL, Pemerintah Daerah merelokasi di tempat yang telah disediakani sehingga tidak ada masyarakat yang di rugikan dan di resahkan dengan keberadaan PKL, agar tercipta keberadaan PKL yang tertib dan sehat.

Untuk memperoleh data dalam penelitian ini, maka peneliti melakukan tehnik pengumpulan data secara:

1) Observasi: peneliti melakukan observasi terhadap PKL yang mangkal dan berada di lingkungan Tegalboto (jalan Jawa, jalan Kalimantan dan jalan Sumatra). Nampak keberadaan PKL yang menggunakan trotoar dan bahu jalan sangat menganggu pengguna trotoar dan pengguna jalan, sehingga menimbulkan kemacetan lalu lintas pada jam efektif. Pejalan kaki tidak bisa menggunakan trotoar karena telah dipadati keberadaan PKL, pada bahu jalan, keberadaan mobil parkirpun secara tidak beraturan karena bahu jalan juga banyak ditempati oleh PKL sehingga menimbulkan kemacetan lalu lintas

2) Wawancara: Peneliti melakukan wawancara dengan beberapa pelaku PKL, antara lain bapak Samuji yang mengaku sudah menjadi PKL di jalan Jawa lebih dari 10 (sepuluh) tahun, yakni dengan berjualan nasi serta lauk pauknya. Diungkapkan bahwa menjadi PKL di jalan Jawa ini mampu memenuhi kebutuhan hidupnya sehari-hari karena setiap hari tidak pernah sepi dari pembeli, Bapak Samuji mampu memenuhi kebutuhan hidup dan menyekolahkan ketiga anaknya, Pada kesempatan lain, peneliti melakukan wawancara dengan bapak Adi yang bekerja di sebuah kantor yang terletak di jalan Kalimantan menyatakan bahwa, setiap hari dari berangkat hingga pulang kantor selalu mengalami kemacetan lalu lintas. Kendaraan roda empat yang digunakan harus berjalan sangat lambat karena macet. Kendaraan roda dua dan pejalan kaki memenuhi lajur kendaraan roda empat, karena mereka menghindari keberadaan PKL yang ada di trotar maupun bahu jalan. Peneliti juga mewancarai petugas satpol PP 
yang mengatakan bahwa PKL bisa tidak berjualan di lingkungan Tegalboto apabila mereka mendengar akan ada penertiban dari satpol PP (razia), tetapi jika tidak ada razia mereka kembali berjualan di lokasi semula.

3) Dokumentasi: Peneliti melakukan pemotretan PKL yang berada di lingkungan Tegalboto.

2. Hambatan

Dalam

Realisasi

Peraturan Daerah Kabupaten

Jember Nomor 6 Tahun 2008 tentang Pedagang Kaki Lima.

Hambatan yang harus dihadapi oleh Satuan Polisi Pamong Praja, diantaranya;

a) Lahan untuk relokasi

Pemerintah kota Jember sudah menertibkan dan menyediakan lahan untuk merelokasi PKL di jalan jawa, seperti lokasi pujasera akan tetapi PKL tidak bersedia karena di anggap tempat yang di sediakan kurang efektif dan kurang strategis serta jauh dari keramaian.

b) Pemahaman Pedagang Kaki Lima tentang Peraturan Daerah

Kurangnya kesadaran dari PKL di lingkungan Tegalboto bahwa keberadaannya sangat membuat tidak nyaman para pengguna jalan, dan keberadaannya yang menimbulkan kemacetan lalu lintas

\section{PENUTUP}

Berdasarkan uraian yang ada, tentang pengaturan Pedagang Kaki Lima (PKL) di Lingkungan Tegalboto berdasarkan Peraturan Daerah Kabupaten Jember Nomor 6 Tahun 2008 tentang Pedagang Kaki Lima di kabupaten Jember, banyak mengalami kendala antara lain relokasi lahan yang kurang strategis, yang membuat PKL keberatan untuk pindah sehingga mempengaruhi keefektifan terwujudnya Peraturan Daerah Nomor 6 Tahun 2008 tentang Pedagang Kaki Lima di Kabupaten Jember.

Berpijak pada kesimpulan maka dapat diberikan saran bahwa, dalam perumusan formulasi kebijakan hendaknya juga melibatkan sasaran kebijakan yang dalam hal ini adalah pelaku Pedagang Kaki Lima, karena sasaran kebijakan selain sebagai pelaku juga orang yang paling tahu keadaan di lapangan sehingga diharapkan dapat membantu pelaksanaan sosialisasi dari implementor atau pelaksana kebijakan. Upaya penertiban PKL harus mendapat dukungan dari berbagai pihak yakni pemerintah, masyarakat dan PKL itu sendiri, agar pelaksanaan kebijakan bisa dilakukan dengan tertib dan tujuan kebijakan dapat tercapai. 


\section{DAFTAR PUSTAKA}

Abidin, Said Zainal. 2016. Kebijakan

Publik. Jakarta: Salemba Humanika Agustino, Leo. 2014. Dasar-Dasar Kebijakan Publik. Bandung: Penerbit Alfabeta

Creswell,J,W.2016. Research Design: pendekatan metode kualitatif, kuantitatif, dan campuran (Edisi ke 4). Yogyakarta: Penerbit Pustaka Pelajar.

Syafri, Wirman dan Israwan Setyoko. 2010. Implementasi Kebijakan Publik dan Etika Profesi Pamong Praja. Bandung: Alqaprint Jatinangor. 